\title{
Visual abstract for Abdominal Radiology: what it is, why we need it and how to make it
}

\author{
Olga R. Brook ${ }^{1} \cdot$ Federica Vernuccio $^{2} \cdot$ Refky Nicola $^{3} \cdot$ Roberto Cannella $^{2,4} \cdot$ Emre Altinmakas $^{5}$
}

Published online: 23 January 2021

(c) The Author(s), under exclusive licence to Springer Science+Business Media, LLC part of Springer Nature 2021

\section{What is visual abstract?}

The visual abstract is a short visual summary of the paper's key points. There are two main characteristics of the visual abstract. First, it should be brief and convey just the most relevant message of the paper. The visual abstract is not expected to be a comprehensive synopsis of the paper, but rather it is designed to allow the reader to skim through multiple abstracts to grasp the key findings. The visual abstract should also be self-explanatory. Its main objective is to engage the reader's interest in order for them to read the entire manuscript. Furthermore, the visual abstract should highlight the most important aspect in a visual format. The main points should be conveyed through graphical images such as figures, diagrams or illustrations. The text should be kept to a minimum and font size large enough to allow for immediate and easy understanding.

\section{Why do we need visual abstract?}

Visual abstracts were first introduced in The Annals of Surgery in July 2016. Since then more than 77 journals [1-4] have adopted this format for the modern pathway to dissemination of scientific information. Abdominal Radiology

Olga R. Brook

obrook@bidmc.harvard.edu

1 Department of Radiology, Beth Israel Deaconess Medical Center, 1 Deaconess Rd, Boston, MA 02215, USA

2 Department of Biomedicine, Neuroscience and Advanced Diagnostics (BIND), University of Palermo, Via del Vespro 129, 90127 Palermo, Italy

3 Roswell Park Cancer Institute, Buffalo, NY, USA

4 Department of Health Promotion, Mother and Child Care, Internal Medicine and Medical Specialties (PROMISE), University of Palermo, Palermo, Italy

5 Koç University Hospital, Istanbul, Turkey published the first visual abstract on 20 June 2020. Visual abstracts are now routinely used on Twitter as well as other social media platforms as a prompt way of disseminating scientific information within the medical community. This allows for even more rapid exchange of scientific information.

By tweeting a visual abstract, there has been added value in the dissemination of scientific information. When comparing tweets of articles by title only vs title and visual abstract, tweets with visual abstract have brought 7.7 times more impressions, 8.4 times more retweets and 2.7 times more article downloads [5]. Social media is definitely changing the landscape of medical education and the exchange of information exchange, especially during this COVID-19 pandemic [6].

\section{How to construct visual abstract for Abdominal Radiology manuscripts}

Visual abstract for Abdominal Radiology should use a standard downloadable template available on the journal website (https://www.springer.com/journal/261/submission-guide lines) with specific background theme and formatting. The abstract should be constructed on a single Powerpoint slide with specified structure (Fig. 1). Background color theme, 
Fig. 1 Template for visual abstract for Abdominal Radiology. Font type: Calibri. The top line should include title of the paper or main goal of the research (font size 28). Body of the visual abstract should include graph/figure/drawing that depicts main finding of the paper. Bottom line will include the first author et al. followed by citation that will be added later by editorial staff on the left and logo of the Abdominal Radiology journal on the right

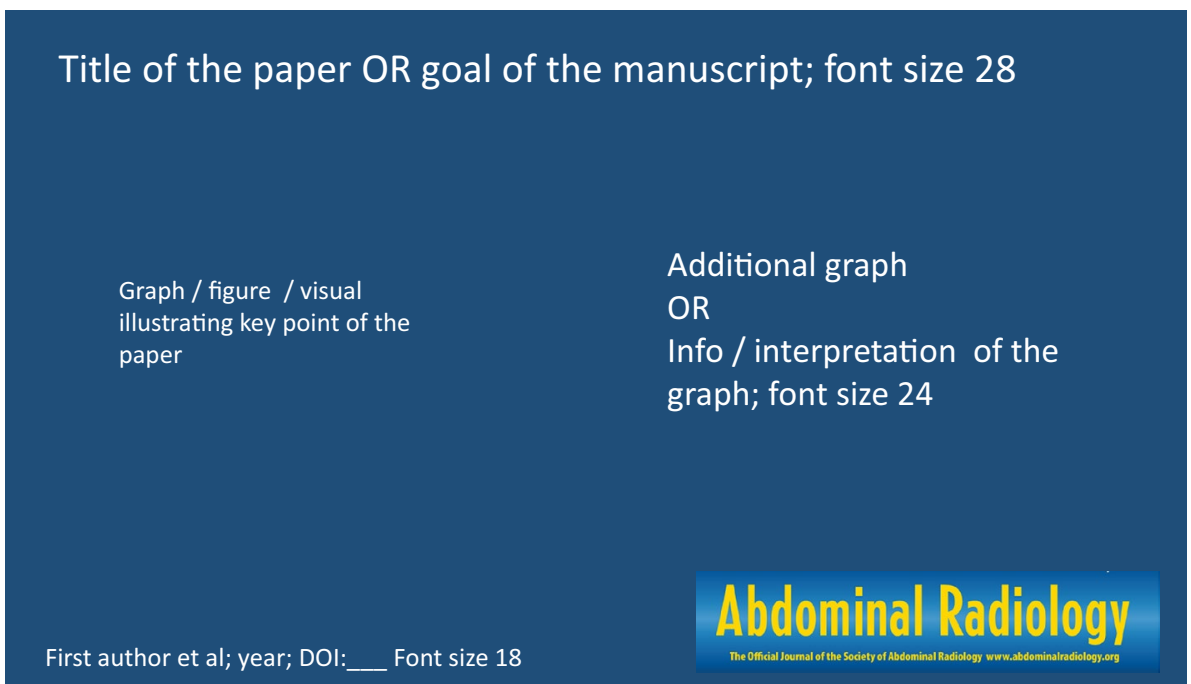

font type, and size should follow the template. Authors should also carefully select one or two images, figures, or drawings that best depict key finding of the paper in a succinct, clear and visual way. In addition, considering that color perception deficiencies are common, certain color combinations_-including red/green, brown/green, blue/ black and blue/purple — should be avoided. Examples of previously published visual abstract are shown in Fig. 2. At the bottom of the slide citation to the article should be included. 
Fig. 2 a-c Previously published visual abstracts in Abdominal Radiology (a)

Infected versus Sterile Abdominal Fluid Collections in Postoperative CT - A Scoring System Based on Clinical and Imaging Findings

\begin{tabular}{|l|l|c|}
\hline \multirow{2}{*}{ CRP } & & Score \\
& $<150 \mathrm{mg} / \mathrm{L}$ & 0 \\
& $\geq 150 \mathrm{mg} / \mathrm{L}$ & 4 \\
\hline CT attenuation & $<20 \mathrm{HU}$ & 0 \\
& $\geq 20 \mathrm{HU}$ & 2 \\
\hline Gas & No & 0 \\
\hline entrapment & Yes & 3 \\
\hline Wall & No & 0 \\
enhancement & Yes & 2 \\
\hline
\end{tabular}

Cutoff to diagnose infected

fluid collections $\geq 5$ points

Score

validated on

93\% sensitivity

425 patients

$80 \%$ specificity

$90 \%$ PPV

$86 \%$ NPV

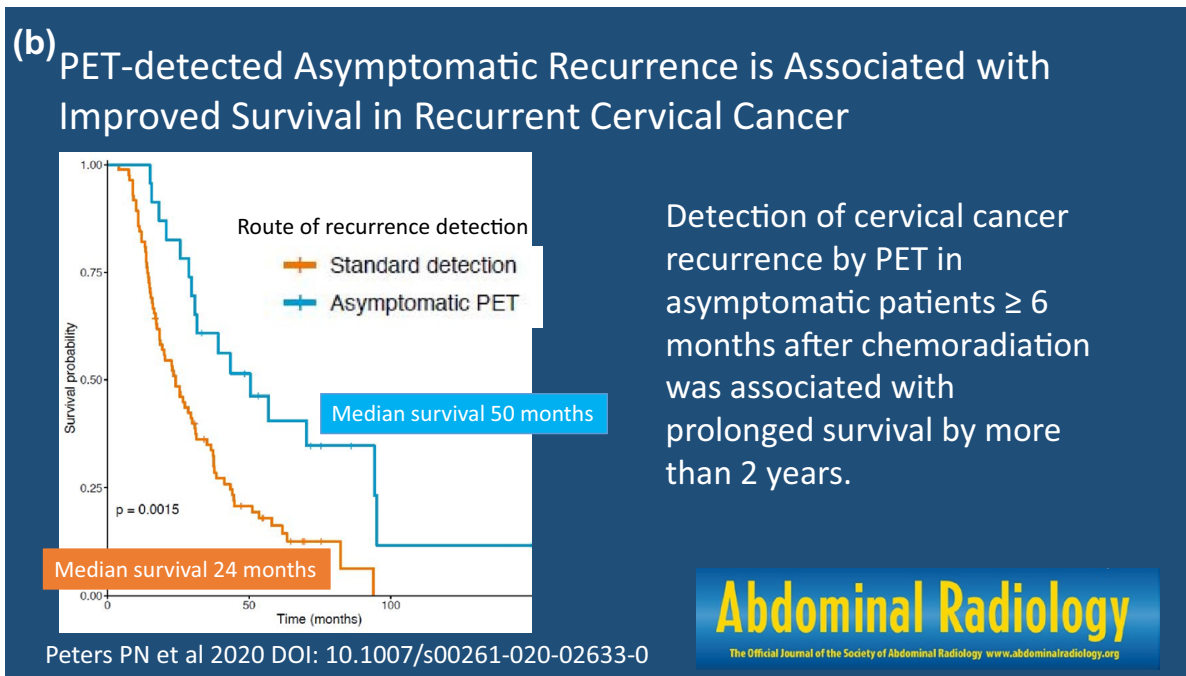

(c)

Preoperative CT predictors of survival in patients with pancreatic ductal adenocarcinoma undergoing curative intent surgery

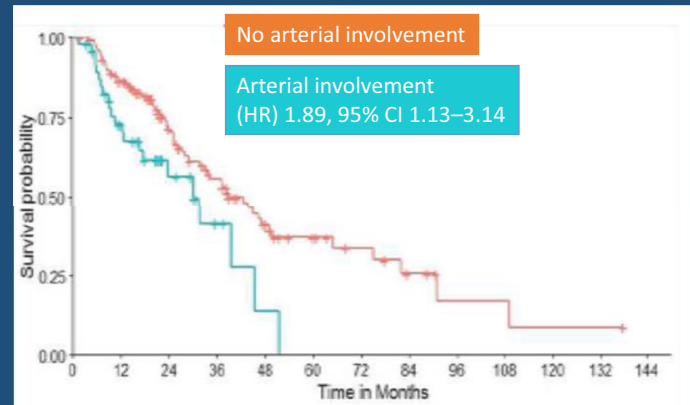

Decreased survival:

Entire cohort:

- CHA involved ( $\mathrm{HR}=2.3)$

- PV deformity (HR=3.2)

In surgical group:

- Tumor size (HR 2.3)

Neoadjuvant group:

- Venous collateral $(\mathrm{HR}=2.3)$ 


\section{References}

1. Fuster V, Mann D. The Art and Challenge of Crafting a Central Illustration or Visual Abstract. J. Am. Coll. Cardiol. Elsevier USA; 2019. p. 2816-2820 https://pubmed.ncbi.nlm.nih.gov/31779 797/. Accessed November 12, 2020.

2. Gloviczki P, Lawrence PF. Visual abstracts bring key message of scientific research. J. Vasc. Surg. Mosby Inc.; 2018. p. 1319-1320.

3. Ramos E, Concepcion BP. Visual Abstracts: Redesigning the Landscape of Research Dissemination. Semin. Nephrol. W.B. Saunders; 2020. p. 291-297 https://pubmed.ncbi.nlm.nih. gov/32560778/. Accessed November 8, 2020.

4. Lindquist LA, Ramirez-Zohfeld V. Visual Abstracts to Disseminate Geriatrics Research Through Social Media. J Am Geriatr Soc. Blackwell Publishing Inc.; 2019;67(6):1128-1131 https:// pubmed.ncbi.nlm.nih.gov/30875100/. Accessed November 12, 2020.

5. Ibrahim AM, Lillemoe KD, Klingensmith ME, Dimick JB. Visual Abstracts to Disseminate Research on Social Media: A Prospective, Case-control Crossover Study. Ann Surg. Lippincott Williams and Wilkins; 2017;266(6):e46-e48https://pubmed.ncbi.nlm. nih.gov/28448382/. Accessed December 1, 2020.

6. Keller DS, Grossman RC, Winter DC. Choosing the new normal for surgical education using alternative platforms. Surg. (United Kingdom). Elsevier Ltd; 2020. p. 617-622 https://pubmed.ncbi. nlm.nih.gov/32904575/. Accessed November 12, 2020.

Publisher's Note Springer Nature remains neutral with regard to jurisdictional claims in published maps and institutional affiliations. 